\title{
Thought Presentation in Nicholas Sparks' \\ The Guardian: A Stylistic Analysis
}

Nahid Ali Mahmoud

Assistant Professor, Faculty of Arts, Beni Suef University, Egypt

\begin{abstract}
This paper explores the categories of thought presentation used by Nicholas Sparks (2003) in an extract from his novel, The Guardian. In this novel, Sparks employs thought presentation extensively. He offers the reader access to the mind of almost every one of his characters, even the dog to whom the title of the novel refers. My aim is to investigate how categories of thought presentation, like Free Direct Thought (FDT), Free Indirect Thought (FIT) and Narrative Report of a Thought Act (NRTA), are used in such a way as to manipulate the reader's
\end{abstract}

perception of, and feelings for the characters involved. Thus, in the extract selected for analysis, the reader's empathy is likely to be established for Mike, the protagonist of the novel, whose thoughts are vividly and directly rendered. On the other hand, the reader is to be distanced from Richard, the antagonist of the novel, whose thoughts are never directly conveyed. The categories of thought presentation to be discussed in the paper are theoretically based on the model devised by Leech and Short (2007) in Style in Fiction.

Keywords: Thought presentation, FDT, FIT, NRTA 


\section{Thought Presentation in Nicholas Sparks' \\ The Guardian: A Stylistic Analysis}

Nahid Ali Mahmoud

\section{Stylistics and the Analysis of Literary Texts}

Since thoughts are not usually processed through words, rendering them through a verbal form becomes a challenging task for both the writer and the reader. This is because the writer has nothing, at his disposal, but words to present what originally cannot be considered verbal, whereas the reader has to recognize both the formal characteristics of the modes of thought presentation used by the writer and the strategic effects achieved by these modes as well. Stylistic analyses of literary texts, to start with, have always been of great importance for both literary texts and language. Semino (2004) indicates that much work in the field of stylistics "involves the in-depth analysis of individual literary texts or extracts, usually in order to relate specific linguistic choices and patterns to potential meanings and effects" (p. 428). Such analysis "represents one of the main strengths of the stylistics tradition " (Semino, 2004, p. 428) as it is capable of providing "invaluable insights into the workings of texts and language generally, as well as useful hypotheses and explanations with respect to readers' interpretations" (Semino, 2004, p. 428). Thus, stylistic analysis of literary texts helps the reader towards a better appreciation of the writer's skills as well as a fuller understanding of the literary work.

Among the main concerns of stylistics is speech and thought presentation. Presenting characters' words and thoughts in a literary text or extract is likely to provide the reader with a considerable amount of knowledge of these characters' emotional states, motives, attitudes and ideologies, on the one hand, and of the technical devices which the writer uses to render the characters' words and thoughts, on the other. One of the most influential and most enlightening studies in this respect is the one made by Leech and Short (2007) in Style in Fiction which serves as the theoretical framework of my paper.

\section{Leech and Short's Model of Speech and Thought Presentation}

It is true that Leech and Short's work was preceded by similar studies (e.g. Pascal, 1977; Cohen, 1978; Chatman, 1978). The model put forward by Leech and Short is, however, "the first to distinguish systematically between the presentation of speech and the presentation of thought in the novel," (Semino \& Short, 2004, p. 22). It is also true that Style in Fiction has been followed by various studies in the field which have adapted and developed the modes of speech and thought presentation put forward by Leech and Short (e.g. Fludernik, 1993; Semino, 2004; Semino \&Short, 2004). Published in 2007, 25 years after the publication of the first edition, the second edition of Style in Fiction takes into account the newer categories of speech and thought which have later emerged like hypothetical and embedded modes. The book also points out to writing presentation which has become a major field for analysis, later added to speech and thought presentation. Leech and Short have even added a whole 
chapter to the second edition of their book, entitled "Stylistics and Fiction: 25 Years on", in which they point out the tremendous changes that have afterwards occurred in the stylistic studies of fiction in general.

\section{Leech and Short's Five Categories of Thought Presentation}

Formally, the categories of both speech and thought presentation " are very similar," as Leech and Short (2007) remark (p. 270). Leech and Short's (2007) categorization of thought presentation parallels that of speech presentation and falls, likewise, into five modes: Free Direct Thought: FDT; Direct Thought: DT; Free Indirect Thought: FIT; Indirect Thought: IT; and Narrative Report of a Thought Act: NRTA (pp. 270-71). But the similarity between speech and thought categories regarding their formal features does not necessitate that the same is true as far as the strategic effects to be achieved are concerned.

\section{The Differences Between Speech and Thought Presentation}

In Semino and Short's (2004) point of view, "although the thought presentation categories largely correspond in formal terms to those" for speech presentation, the effects produced are totally different ( $\mathrm{p}$. 118). This is due to the fact that using language to present thoughts "involves 'translating' into words a phenomenon that might have consisted of non-verbal cognitive activities" (Semino \& Short, 2004, p.118). Consequently, the norm for thought presentation is different from that of speech presentation. Leech and Short (2007) maintain that the norm for speech presentation is Direct Speech (DS), not Indirect Speech (IS), whereas in thought presentation the norm is IT, not DT. This is because in the case of speech presentation, " DS is possible, and indeed common, because it is the mode that represents speech in the form in which it is directly manifest to a listener" (Leech \& Short, 2007, p. 276). On the other hand, in the case of thought presentation, the thoughts of others " are not accessible to such direct perception" (Leech \& Short, 2007, p. 276), and are, therefore, more likely to be presented through IT which is more convenient as a mode to be the norm for presenting thoughts which are not "verbally formulated, and so cannot be reported verbatim" (Leech \& Short, 2007, p. 276).

Leech and Short (2007) elaborate on the difference between speech and thought presentation maintaining that "the more direct forms of [thought] presentation, DT and FDT, take on a somewhat different value from their speech counterparts" (p. 274). In DT and FDT, like in DS and Free Direct Speech (FDS), "authorial intervention appears minimal" (Leech \& Short, 2007, p. 274). In DS and FDS, we, thus, get a faithful reproduction of what a character says and in DT and FDT, we are shown inside the character's mind. The effect produced is, however, totally different, because in the case of DT and FDT, "the result is effectively a monologue" and, therefore, the character's thoughts "acquire a conscious quality" (Leech \& Short, 2007, p. 274). This underlines how far significant the use of DT and FDT is for rendering the thoughts of a character, with the intervention on the author's part being at its minimum. Still, Leech and Short (2007) go on to indicate: "Because the direct perception of someone else's thought is not possible, DT is perceived as more artificial than more indirect forms." (p. 277). FDT, however, can be regarded as less artificial than DT, due to the removal of the quotation marks and /or the reporting clause in the FDT mode. The conscious quality of the thoughts is thus produced with less and 
less artificiality, signifying the reader's access to the character's mind where he can follow the thoughts at the same time they occur.

\section{The Need for Thought Presentation}

Presenting a character's thoughts is, therefore, not an easy task. Yet, Leech and Short (2007) maintain that "if the motivations for the actions and attitudes of characters are to be made clear to the reader, the representation of their thoughts, like the use of soliloquy on stage, is a necessary licence" (p. 270). As a matter of fact, readers do not find a problem in accepting the idea that characters' thoughts are being presented in fiction. McKenzie (1986) indicates that readers "readily accept that, in fiction, they have privileged access to the interiors of other minds in a way which they never do in daily reality. . ." (p.42). Because readers do accept that thoughts could be presented in fiction, though not in real life, thought presentation has received great attention from novelists. This has, in turn, led to the emergence of " various experimental techniques" (Leech \& Short, 2007. p. 270) which not only " report what the character thinks," but also "render the character's immediate experience or consciousness of those thoughts" (Leech \& Short, 2007. p. 270). Leech and Short (2007) emphasize the extensively conscious effect achieved by DT and FDT, stating:

When DT is used, the writer is in effect saying, "This is what the character would have said if he had made his thoughts explicit". It is this explicitness which gives rise to the conscious qualities of DT and FDT. (p. 277)

So, DT and FDT, in particular, are often used to reveal characters as if they are speaking their thoughts to themselves out loud.
It is worthy of note that owing to the highly conscious effect it produces, FDT was significantly referred to as "interior monologue" (Chatman, 1978, p. 182) and "quoted monologue" (Cohn, 1978, p. 496). In Leech and Short's (2007) view, moving "along the scale towards the 'free' end of the thought presentation continuum, we apparently get the 'verbatim' thoughts of the characters with less and less intervention on the writer's part." (p. 271). This, in turn, immensely contributes to the freshness and immediacy of the thoughts revealed.

As for FIT, Leech and Short (2007) notably compare it with its counterpart in speech, FIS, maintaining that "while FIS distances us somewhat from the characters producing the speech, FIT has the opposite effect, apparently putting us directly inside the character's mind." (p. 276). To Leech and Short (2007), "FIT is seen as a move . . . away from the author's most directly interpretative control and into the active mind of the character" (p. 277). Whereas FDT retains all the lively aspects of DT without the quotation marks and/or the reporting clause, FIT keeps "much of the vividness of DT without the artificiality of the 'speaking to oneself' convention" (Leech \& Short, 2007, p. 277). Semino (2004) points out that the forms of free indirect thought in particular have been given more attention from literary critics and linguists, " largely due to their linguistic versatility and to the nature and complexity of their possible effects." (p. 438).

In contrast to DT, FDT and FIT, NRTA is the mode of thought presentation which largely distances the reader from the character whose thoughts are being presented. This is because NRTA strongly marks the narrator's voice. As Leech and Short (2007) indicate, NRTA is "an extremely indirect form " (p. 270) of 
thought presentation which provides the reader with the briefest account of the character's thought.

\section{The Distinguishing Features of Thought Presentation Modes}

Like their counterparts of speech, modes of thought presentation, Leech and Short (2007) indicate, "can be distinguished by features from any of the three levels of grammar, lexis and graphology" (p. 271). As for grammar, this level includes features like the use of tenses, pronouns, interrogation, and exclamation forms. Concerning lexis, it is related to the use of expressive words like deictics and value-laden words. Finally, graphology is related to how words appear to the reader, and this includes elements like spelling, punctuation and paragraphing which "become noticeably expressive only when a writer makes a graphological choice which is to some degree marked or unconventional such as a deliberate misspelling" ( Leech \& Short, 2007, p.105), or the use of capitaization and italics with the purpose of emphasizing a particular tone.

\section{The Extract for Analysis}

The Guardian is a romantic thriller in which the reader is introduced to Julie Barenson, the young widow whose loving, devoted husband died when she was only 25 years old. Four years after his death, Julia is trying to start her life anew, especially when she meets Richard Franklin, the handsome, decent and rich gentleman. There is also Mike Harris, the intimate friend of Julie's late husband who is deeply in love with her. The extract under discussion appears very early in chapter 6 of the novel, which consists of 42 chapters, immediately after Julie introduces Richard to Mike one night, when all three meet at a bar. The extract shows the reader into Mike's mind, presenting his thoughts of and reflections on that sharp feeling of uneasiness which suddenly strikes him in Richard's presence. Though it is natural for Mike to feel jealous of Richard, Mike's feelings against him seem ominous, and, later in the novel, prove to be true since Richard would turn out to be psychopathic.

In the extract, the access to Mike's mind which Sparks (2003) offers to the reader, determines the angle from which the reader is meant to see the event. According to Leech and Short (2007), if a writer " decides to let us know the thoughts of a character at all", this means that he " is inviting us to see things from that character's point of view." (p. 271). This is exactly what Sparks is trying to do in the extract. He uses thought presentation to convey to us Mike's uneasiness and confusion on first meeting Richard. Mike is trying to find out what exactly makes him feel that way. He becomes certain that it cannot be merely jealousy, but it is something he reads in Richard's eyes which terribly alarms him. In Richard's eyes, he shockingly reads nothing but inexplicable hostility and cruelty. As a result, the extract very early arouses the reader's suspicions concerning Richard's character, suspicions which would be later validated in the novel. The extract is, therefore, immensely significant since it very early anticipates the serious problems Richard will involve many people in.

The sentences in the extract are numbered in order that they can be easily referred to.

(1) Besides the obvious.

(2) No, there was more to it than just that.

(3) No matter what Henry [Mike's brother] had said or what Julie seemed to think, Richard didn't strike Mike as a particularly nice guy. 
(4) What happened at the bar made that plain.

(5) Once he'd said what he had about Julie, Richard had looked at him as if already recognizing Mike's feelings for her, and his face clearly expressed what he thought about that: You lose, so stay away.

(6) Not exactly the hallmark of a nice guy.

(7) So why didn't Julie seem to see the side of Richard that he did? (8) And why didn't Henry or Emma [Henry's wife]? (9) Or was the whole thing just a figment of his imagination?

(10) Mike ran through the scenario again. (11) No, he finally decided, I didn't imagine it. (12) I know what I saw. (13) And I don't like him.

(14) He leaned back in his chair, taking a deep breath as he scanned the room. (15) His eyes found Richard and Julie, and he watched them for a moment before he forced himself to turn away.

(16) During the band's break, Julie and Richard had left the dance floor and found a smaller table on the far side of the bar, and Mike had been glancing their way ever since. (17) He couldn't help it. (18) Though he tried to pretend that he was still trying to figure Richard out, he knew his compulsion to watch had more in common with what people feel when they come across the scene of a grisly accident. (19) Or even more accurately, he thought, watching them together was like watching a car plunging off a monstrous cliff, with a bird's-eye view through the windshield.

(20) That's how it seemed, anyway. (21) As the night wore on, he couldn't escape the conclusion that his chance with Julie was suddenly going the way of Atlantis. (22) While Mike was sitting by himself, Julie and Richard were staring into each other's eyes with goofy grins on their faces. (23) They were leaning in to whisper and laugh, obviously enjoying each other's company.

(24) Disgusting.

(25) At least the last time he'd looked, just a few seconds ago.

(26) But what, he wondered, were they doing now?

(27) Slowly, ever so subtly, Mike's eyes began to travel their way again. (28) Julie was facing the other direction, so thankfully she wouldn't see him watching her. (29) If she caught him staring, she might wave at him, or nod and smile, or worse, ignore him. (30) The first two would make him feel like an idiot, the last one would break his heart.

(31) As he turned, he saw Julie rummaging through her purse for something, her eyes focused in her lap.

(32) Richard's eyes, though, locked on his in a cool, almost confident appraisal. (33) Yes, Mike, I know you're staring.

(34) Mike froze, a kid caught pulling a twenty from his mother's wallet. (Sparks, 2003, pp. 70-2)

\section{Analysis and Discussion}

\section{Free Direct Thought: FDT}

The truncated quality of sentence 1, "Besides the obvious" (Sparks, 2003, p. 70 ), which occupies a separate line in the extract represents the free variation of DT and makes it easy for the reader to realize that it is FDT. Despite its truncated quality, the sentence does make sense when read as a thought. Commenting on the great difference between the nature of speech and that of thought, McKenzi (1986) believes that "people think to 
threatening tone which the reader will not fail to recognize. Choosing FDT to present Richard's thoughts adds an enhanced conscious quality to what is going on inside Richard's mind, and reveals the shocking effect his thoughts have on Mike. Those unspoken words serve as Richard's very first threat in the novel directed toward Mike who would get into serious troubles simply because he would not " 'stay away' " (Sparks, 2003, p. 71).

The extract under discussion significantly precedes the alarming scene in chapter 9 where Richard gets mad with anger when he would not see the necklace - he has previously offered to Julie as a present - around her neck. Richard's unexpected incomprehensible nervousness and overreaction will then remind the reader of this extract, namely when the reader recalls Richard's aggressive nature revealed through the unspoken threat Mike has read in his face three chapters earlier.

In sentence 6, "Not exactly the hallmark of a nice guy" (Sparks, 2003, p. 71), the use of the word "nice" in italics, indicates that it is Mike's and not the narrator's. Thus the italicized "nice" and the truncated quality of the sentence are both features to distinguish the sentence as FDT. This in turn lends a further conscious quality to Mike's thought, largely contributing to its presentation as freshly and vividly as it goes by inside his mind.

When a bit earlier, while both Richard and Mike are sitting at the bar, Mike remains silent for a while before he finally describes Julie as " 'a great lady' " (Sparks, 2003, p. 69). Richard, on the other hand, does not answer immediately. He "turned and seemed to study him [Mike] before turning away again: 'Yes, she is' he said simply" (Sparks, 2003, p. 69). Going through the details of this earlier scene with Richard at the bar leaves Mike certain of what he feels. Now he believes that he 
is not imagining anything. He does not like Richard because of what Richard, through his body language, has communicated to Mike and because of the tone of Richard's remarkably brief words. This certainty is presented through sentences 11- 13 which are all FDT. Sentence 11, "No, he finally decided, I didn't imagine it" (Sparks, 2003, p. 71), has FDT and inversion which both reveal how definitely sure and strongly decisive Mike has become when he reaches the conclusion that "he didn't imagine it." The use of the expressive word, "No" and the retention of the firstperson pronoun are both aspects of directness, whereas the removal of quotation marks indicates that the sentence is a free variation of DT. Still the use of the past tense does not affect the directness aspect of the sentence since Mike's realization that he did not imagine the whole thing is what is related to his consciousness at the moment. He seems to think: Now, I realize that I did not imagine it. This is emphasized through sentence 12, "I know what I saw" (Sparks, 2003, p. 71), which has the verb "know" in the present simple tense and "saw" in the past simple tense. In this sentence as well as in sentence 13, "And I don't like him" (Sparks, 2003, p. 71), the absence of a reporting clause makes the conscious quality more powerfully felt. The sequence of Mike's thoughts is thus vividly created and rendered with the minimum intervention on the narrator's part in sentence 11 , through the use of the reporting clause "he finally decided" (Sparks, 2003, p. 71); and with no intervention of the narrator at all in sentences 12 and 13 .

Sentence 20, "That's how it seemed, anyway" (Sparks, 2003, p. 71), is closely related to sentence 19, "Or even more accurately, he thought, watching them together was like watching a car plunging off a monstrous cliff, with a bird's-eye view through the windshield" (Sparks, 2003 , p. 71). In other words, one can say that sentence 20 sums sentence 19 up and is, therefore, better read as one of Mike's thoughts presented as FDT with the spontaneous effect of "anyway" and the present tense as both features of directness, together with the removal of both the quotation marks and the reporting clause as an indicator of its being a free variation of DT.

Sentence 24, "Disgusting" (Sparks, 2003 , p. 71), is FDT, with its truncated quality and the removal of both the quotation marks and the reporting clause. The sentence is Mike's unspoken comment on seeing Julie and Richard whispering and laughing in sentence 23. Presented through one single word, this thought could be a good example of what is known as the extreme of FDT as Leech and Short (2007) remark (p. 292). It underlines Sparks' attempt to present through words a process which is not verbal and cannot be as much systematized and organized as words are.

Sentence 33, "'Yes, Mike, I know you're staring"" (Sparks, 2003, p. 72), is Richard's thought presented as FDT, with the removal of both quotation marks and the reporting clause. It is communicated through Mike's thoughts. Hence, it can be read as an embedded thought, namely a thought within thought, the same as sentence 5. This thought strikes the reader as much chilling as it does Mike.

\section{Free Indirect Thought: FIT}

In order to emphasize the immediacy and vividness of Mike's thoughts, Sparks (2003) follows sentence 1 which is FDT with FIT in sentence 2, "No, there was more to it than just that" (p. 70). This shift from FDT to FIT can be easily noticed through the use of the expressive word "No" which indicates a feature of 
directness, together with the use of the past tense which makes it clear that the thought is indirectly presented. Thus, the combination of features of both directness and indirectness makes the thought fall into the category of FIT. "Like the direct forms," Leech and Short (2007) indicate, "the free indirect form takes on a different value when we turn from the presentation of speech to the presentation of thought" (p. 275). Leech and Short (2007) go on to explain: "Instead of indicating a move towards the narrator," FIT can be seen as "a movement towards the exact representation of a character's thought as it occurs:" (p. 275). Hence, in spite of the shift to FIT in sentence 2, we are still inside Mike's mind. It is true that the narrator's voice is there - through the back-shift of the tense- but it is limited and kept to the minimum.

Sentence 3, "No matter what Henry had said or what Julie seemed to think, Richard didn't strike Mike as a particularly nice guy" (Sparks, 2003, p. 70), could have been read as NRTA with the word "strike" being obviously the narrator's to describe the impression Richard has left on Mike. But then comes the evaluative word "nice" in italics to change the sentence into FIT, as the reader is more likely to read this word as being Mike's, not the narrator's. The sentence, thus, reflects the strong discomfort Mike feels towards Richard regardless of how much positively his brother Henry and Julie think of him.

As for sentence 4, "What happened at the bar made that plain" (Sparks, 2003, p. 70), the use of "that" signifies the previous thought in sentence 3. This, therefore, makes sentence 4 read as FIT, since it becomes strongly associated with sentence 3 which is originally FIT. Both sentences further emphasize the inexplicable uneasiness Mike feels towards Richard.
Sentences 7-9 can all be read as FIT revealing Mike's utter confusion while reflecting on his thoughts and asking himself questions he cannot find answers to. On the one hand, all three sentences have back-shift of the tense ("didn't" and "did" in sentence 7; "didn't" in sentence 8; and "was" in sentence 9) and sentences 7 and 9 have conversion in the pronouns ("he" in sentence 7, and "his" in sentence 9), which are all features of indirectness; on the other hand, the sentences retain the interrogative form and the question marks which are features of directness. The vividness and immediacy of Mike's thoughts, thus, produced by the aspects of directness are enhanced by the removal of the quotation marks and the reporting clause. The aspects of indirectness, on the other hand, help convey to the reader Mike's baffled state of mind while he is reflecting on the way he feels towards Richard and on his inability to grasp his inexplicable hatred of Richard whom he meets for the first time.

Both sentence 17 "He couldn't help it" (Sparks, 2003, p. 71) and sentence 18 "Though he tried to pretend that he was still trying to figure Richard out, he knew his compulsion to watch had more in common with what people feel when they come across the scene of a grisly accident" (Sparks, 2003, p.71) might have been read as narrative, descriptive statements by the author, but for sentence 19, "Or even more accurately, he thought, watching them together was like watching a car plunging off a monstrous cliff, with a bird's-eye view through the windshield" (Sparks, 2003, p. 71) and sentence 20, "That's how it seemed, anyway" (Sparks, 2003, p. 71). Sentence 19 , to start with, is a combination of FIT and inversion. It is this inversion together with the use of "Or" which reveals a strong association with sentence 18 and makes it more conveniently read as FIT, too. It becomes clear that sentences 
18 and 19 are originally Mike's thoughts, and though sentence 19 might have been read as IT, when followed by sentence 20 it becomes FIT. This is due to the use of "that" which refers back to Mike's thoughts in sentences 17, 18 and 19; and the use of "anyway" with the spontaneous effect it produces. And since both sentences 18 and 19 explain sentence 17 so, it is more probably to read sentence 17 itself as one of Mike's thoughts presented as FIT with the removal of the reporting clause. The reader is more likely to understand it in this way: He thought that he could not help it. It is worthy of note that the two similes that Mike forms, namely the one of "grisy accident" in sentence 18 and the one of the car "plunging off a monstrous cliff" in sentence 19 are strongly associated with his work as a mechanic, an association which is in accordance with the way a mechanic thinks. This in turn further emphasizes that the two sentences are in fact FIT with the two similes being created inside Mike's mind. These similes also mirror the threatening danger Mike is able to foresee, very early in the novel, through the relationship of Julie and Richard.

Sentence 21, "As the night wore on, he couldn't escape the conclusion that his chance with Julie was suddenly going the way of Atlantis" (Sparks, 2003, p. 71), is FIT only because of the retention of the expressive phrase "going the way of Atlantis" which can be easily attributed to Mike, not the narrator. The sentence reflects Mike's realization that if he could ever have a chance with Julie, it is thwarted away all of a sudden after his brief encounter with Richard.

The use of the word "goofy" in sentence 22, "While Mike was sitting by himself, Julie and Richard were staring into each other's eyes with goofy grins on their faces" (Sparks, 2003, p. 71), and "obviously" in sentence 23, "They were leaning in to whisper and laugh, obviously enjoying each other's company" (Sparks, 2003, p. 71) make the two sentences fall into the category of FIT, since they are value-laden words which are more likely to be read as Mike's, not the narrator's.

Because sentence 25, "At least the last time he'd looked, just a few seconds ago" (Sparks, 2003, p. 71), directly refers to sentence 24, "Disgusting" (Sparks, 2003, p. 71), so it is FIT, especially with the use of "At least" at the very beginning of the sentence and "just" as features of directness producing a spontaneous effect, combined with the conversion of the pronoun "he" and the back-shift of the tense as feature of indirectness. Sentence 25 could thus be read as a continuation of sentence 24 .

In sentence 26, "But what, he wondered, were they doing now?" (Sparks, 2003, p. 72), Mike's curiosity to look and see what Julie and Richard are doing is suddenly aroused once again. This is clearly revealed through both inversion and FIT. The inversion lends the thought a further conscious quality, and the retention of the question mark and the interrogative form together with the use of the near deictic "now" enhances the vividness and the immediacy of the thought.

Also, sentence 28, "Julie was facing the other direction, so thankfully she wouldn't see him watching her" (Sparks, 2003, p. 72), can be read as FIT because of the use of the value-laden adverb "thankfully". The adverb is easily attributed to Mike, and hence it is only because of this word that the sentence becomes FIT. The reader will not fail to notice that it is Mike who feels thankful that Julie doesn't see him watching her.

Again in sentence 29, "If she caught him staring, she might wave at him, or nod 
horror of a little child who is caught while stealing money from his mother's wallet.

\section{Narrative Report of a Thought Act: NRTA}

In sentence 10, "Mike ran through the scenario again" (Sparks, 2003, p. 71), we have a perfect example of what Leech and Short (2007) describe as NRTA, namely that the sentence "incorporates what minimal report there is within the main clause by nominalising the reported clause" (p. 271). Sparks, very elliptically, points out to the train of thoughts repeated again inside Mile's mind. The reason why Sparks uses NRTA in this sentence is possibly to avoid being boring and redundant. The sentence very briefly indicates that Mike has reviewed the whole event once again, revealing the author's intervention at its most and keeping the reader away from the inside of Mike's thought, in one of the very rare occurrences in the extract.

\section{Conclusion}

Strongly associated with sentence 33, "'Yes, Mike, I know you're staring"" (Sparks, 2003, p. 72), is sentence 34, "Mike froze, a kid caught pulling a twenty from his mother's wallet" (Sparks, 2003, p. 72). The terrifying effect of Richard's unspoken words in sentence 33 on Mike is powerfully depicted in sentence 34 . Mike suddenly feels as if his eyes were seized by Richard; he is extremely shocked by the idea that Richard has been aware of his looks all the time. The image used in sentence 34 is much likely to make the sentence read as FIT. The use of the informal word "a twenty", in particular, makes the sentence fall into the category of FIT, since the word is more likely to be attributed to Mike than to the narrator. Stunned by what he unexpectedly reads in Richard's eyes, Mike feels the freezing 
freshness. The FDT mode is employed to add an enhanced conscious quality to these thoughts as they are presented at the same moment they go by inside Mike's mind. The characteristic features of the sentences belonging to FDT mode in the extract vary between the use of the truncated form of sentences, the retention of both the interrogative form and question marks, the retention of the present simple tense and the first-person and second-person pronouns, the removal of both quotation marks and reporting clauses, the use of near deictics and value-laden expressive words, and the use of italicized words. It is worthy to note that the FDT examples are comparatively fewer than the FIT ones. This is mainly because the extract underlines Mike's reflection on his own impressions after meeting Richard for the first time.

As for the forms of FIT, Sparks (2003) uses them to render Mike's thoughts with vividness, immediacy and freshness but without the artificiality that might be inherent in FDT. This is achieved through combining aspects of directness (near deictics, expressive words and retention of interrogative forms and question marks) with aspects of indirectness (backshift of the tense and conversion of pronouns) together with the use of inversion.

Concerning NRTA, it is the least category used in the extract for it is employed for only one time. This is due to the distancing nature of this mode of thought presentation. It is the mode which keeps the reader away from the details of the character's thoughts, whereas Sparks (2003) intends to show the reader into Mike's mind.

Due to the various categories of thought presentation employed by the author, especially FDT and FIT, the extract shows Mike as trying to dig deeper than what might be presumed to be a natural feeling of jealousy towards Richard. This effort on Mike's part to be objective makes his doubts and fears concerning Richard sound credible, and they are, thus, easily and convincingly conveyed to the reader. Three chapters later, Mike's inexplicable doubts and fears are gradually validated as the action develops and Richard's mental disorder is revealed. 


\section{References}

Chatman, S. (1978). Story and discourse: Narrative structure in fiction and film. Ithaca, NY: Cornell University Press.

Cohn, D. (1978). Transparent minds: Narrative modes for pesenting consciousness in fiction. Princeton NJ: Princeton Un_versity Press.

Fludernik, M. (1993). The fictions of language and the languages of fiction. London, England: Routledge.

Leech, G., \& Short, M. (2007). Style in fiction: A linguistic introduction to English fictional prose (2nd ed.). Harlow, England: Pearson Longman.

McKenzie, M. (1986). On the presentation of speech and thought in narrative fiction. Theoria: A Journal of Social and Political Theory, (68), 37-48. Retrieved from http://www.jstor.org/stable/41801752

Pascal, R. (1977). The dual voice: Free indirect speech and its functioning in the nineteenth century European novel. Manchester, England: Manchester University Press.

Semino, E. (2004). Representing characters' speech and thought in narrative fiction: A study of England, England by Julian Barnes. Style, 38(4), 428-451. Retrieved from http://www.jstor.org/stable/10.5325/style.38.4.428

Semino, E., \& Short, M. (2004). Corpus stylistics: Speech, writing and thought presentation in a corpus of English writing. London, England: Routledge.

Sparks, N. (2003). The guardian. New York NY: Grand Central Publishing. 